\title{
Aging, Disability, and Frailty: Implications for Universal Design
}

\author{
Douglas E. Crews and Susan Zavotka \\ Departments of Anthropology and Consumer Sciences, The Ohio State University, USA
}

\begin{abstract}
Throughout the world all populations are seeing burgeoning numbers of "elders", defined as persons aged 65 year and older. In many countries, including Japan, the United States, Norway, Sweden and the United Kingdom, those aged over 65 are at or approaching $15 \%$ of the population. As their numbers have increased, so have their health care expenses, leading to extensive research on the health, well being, and life expectancy of these increasingly older elders. Today this group is further sub-divided: the young-old ages $65-74$, the old-old ages $75-84$, and the oldest-old ages $85+$, for both health care and research purposes. However broad variation still characterizes even these groupings. Rates of frailty and disability increase with increasing age among these elders. For example, inabilities to complete at least one activity of daily living increased from about 5-7\% at ages 65-69 years to about $28-36 \%$ at ages $85+$ in 1987 . Death rates continue to decline at all ages past 50 years and rates of disability seem to be doing the same. For the foreseeable future, we may expect increasing numbers of older, frail elders than in previous decades. Thus, people are not only living longer, they generally are healthier at advanced ages than were previous cohorts, thus "old age" disabilities of the 20th century will be put off to even older ages during the 21 st century. As yet there is no clear way to assess senescent changes in humans, although activities of daily living, allostatic load, and frailty indices have all been suggested. One future need is greater development and use of universal and accessible design in all aspects of the built environment. J Physiol Anthropol 25(1): 113-118, 2006 http:// www.jstage.jst.go.jp/browse/jpa2
\end{abstract}

[DOI: 10.2114/jpa2.25.113]

Keywords: elders, senescence, built environments, artificial environments

\section{Introduction}

Elders frequently are defined as persons aged 65 years and over (Crews, 2005; Susman and Riley, 1985). For health care and research purposes these elders often are subdivided into the young-old (65-74 years), the old-old (75-84 years), and the oldest-old (85+) (Susman and Riley, 1985). The number of elders in each category is increasing throughout the world, and these elders also are surviving longer than ever before in human history (Harper and Crews, 2000). Nations such as Japan, Sweden, Great Britian, the USA, and Norway now are approaching or already have over $15 \%$ of their population aged $65+$ years (Crews, 2005). Growing numbers of older citizens worldwide are placing new stresses on their families, communities, and countries, including increased needs for health care, in-home care-giving, and appropriate housing. As noted elsewhere, most elders are neither frail nor incapable of independent living (Crews, 2003, 2005; Harper and Crews, 2000). However, their numbers are increasing worldwide and most national populations are seeing increased health care costs for their aging populations (Crews, 2003; Harper and Crews, 2000). In addition, the rapid increase in elders during recent decades has been a boon to gerontological research on the health, well-being, and life expectancy of increasingly older elders. One area of recent research activity has been developing designs for interior and exterior built spaces that enhance the well being and activities of elders in their own homes and public facilities. An entire area of research is currently being developed around the concept of universal design (UD) of products and built environments for usability by all individuals without needs for specialized designs to ensure accesible design for all.

At present, there is no clear way to assess senescent change in humans, although for some time a number of indicators of senescence have been used in non-human animal models (Amdam, 2005; Carey and Papadopoulos, 2005; Murphy, 2005). For aging human populations there are two important needs for future research. First is to develop consistent and cross-culturally valid methods for assessing frailty associated with senescent change. Second is how to design environments appropriate for the proportion of elders who are increasingly frail and disabled but whose survival continues to improve. This paper briefly reviews demographic and disability changes affecting elders, examines some methods for assessing frailty in elders, and reviews aspects of environmental design that may aid not only elders with reduced abilities to complete activities of daily living (ADLs) (Katz et al., 1963), but 
increase accesibility for individuals of all ages who have limitations or are frail.

\section{Demographic Considerations}

In almost all populations, whether cosmopolitan or traditional, death and disability rates at all ages continue to decline (Crews, 2005). Mortality rates during infancy and childhood were the first to decline among Western cosmopolitan populations (Teitlebaum, 1975; Omran, 1971). Subsequently, mortality among reproductive-age adults and elders declined. Today, mortality rates are declining most at ages over 65 and life span is increasing most rapidly at ages over 75 years (Harper and Crews, 2000). For the foreseeable future, almost all governments may expect increasing numbers of elders. On average more of these new elders may be expected to survive to older ages than did previous birth cohorts and at the same time to be healthier. Increased survival leads not only to increasing numbers of healthy elders, but also frail and disabled elders.

People not only live longer today, they generally are healthier at advanced ages than were previous birth cohorts. "Old age" disabilities that plagued the young-old of the 20th century are now being put off to older ages where they affect the old-old and oldest-old of the 21st; this is similar to how age-related disabilities of the 19th century were pushed to older ages during the 20th century (see Crews, 2003). 21st century elders in cosmopolitan settings are already healthier and less disabled than were earlier cohorts at the same ages. The number of disabled elders continues to increase simply due to the large proportion surviving to older ages today, particularly among the "Baby Boom" cohort (Harper and Crews, 2000). Additionally, more persons also will survive into their 10th and later decade of life during the 21 st century than ever have before. At least in part, how well these elders live and their abilities to maintain independent life styles will depend on their health and the degree to which they have remained able as opposed to frail and disabled. This in turn, will depend to at least some extent on how well the artificial and built environments in which they live conform to their needs and their age-related losses in abilities and somatic integrity.

\section{Frailty and Disability}

Although rates of frailty and disability tend to increase with increasing age, large variations in health, well-being, disability, and health care needs characterize different groups of elders. For example, in 1987 in the US, the inability to complete at least one ADL increased from about 5-7\% at ages 65-69 years to about $28-36 \%$ at ages $85+$ (Brock et al., 1990). In 1984, among US non-institutionalized adults $15 \%$ of men and $18 \%$ of women aged 65-74 had difficulty completing at least one ADL, while $40 \%$ of men and $53 \%$ of women aged $85+$ were similarly disabled (Brock et al., 1990; reviewed in Crews
$2005)$. In 1987 , only $5 \%$ of men and $5 \%$ of women aged $65-69$ reported difficulty completing at least one ADL, as did $26 \%$ of men and $35 \%$ of women age $85+$ (Rakowski and Pearlman, 1995). In the US National Long-Term Care Surveys, selfreported disability also declined, from $24.9 \%$ in 1982 to $21.3 \%$ in 1994 (Manton et al., 1997). These data suggest that today's elder's are healthier and less disabled than were previous cohorts.

Assessments of ADLs have improved somewhat our ability to determine level of disability in both elder and younger cohorts. ADLs include bathing, dressing, transferring, feeding, ambulating, and toileting (Katz et al., 1963). Instrumental Activities of Daily Living (IADLs) include using a telephone, grooming, shopping, housekeeping, and taking medicine properly (reviewed in Harper and Crews, 2000; Crews, 2005). In the most recent representative sample available (Federal Interagency Forum of Aging Related Statistics, 2000), men reported greater disability in ADLs than did women at all ages, with a low at ages $65-69$ of 5\% and 4\% for men and women, and a high of $37 \%$ at age $85+$ for men and $35 \%$ for women.

Obviously, disability, as determined by self-reports of ADLs and IADLs, is being pushed to later decades of life in cosmopolitan settings. Data also show that as more people survive to older ages, they are healthier, less frail, and less disabled than were previous cohorts at these same ages. Increases in chronic degenerative conditions (CDCs) and their disabling sequlea with increasing age are well documented among elders (Crews, 2003). These will continue to plague those who survive to older ages. Thus, more people also are surviving CDCs to older ages, and most are healthier and more active than ever before. Still CDCs predispose some individuals to greater somatic stress, increased disability, loss of ADLs, and additional opportunities for frailty to increase. In addition to $\mathrm{CDCs}$ and disability, general declines and alterations in motor coordination, spatial perception, visual and auditory acuity, gait, muscle and bone strength, mobility, and sensory perceptions of environmental stimuli (heat and cold) are well documented after age 65 (Arking, 2005; Beall, 1994; Crews, 2003, 2005; Harper and Crews, 2000). Many of these later problems are associated with increasing frailty and physiological senescence, particularly among elders, but they also affect non-elders.

Frailty, a complex biological phenomenon, is closely associated with pathology and disease in most physicians' and patients' minds. However, this intuitive understanding of frailty does not suffice for a medical/scientific model or definition of frailty. Frailty represents multiple alterations in physiological functioning and processes that lead to a decreased ability to complete necessary tasks. But frailty is not necessarily the outcome of pathology and disease. Frailty includes such alterations as decreased mobility, strength, and responsiveness to external and internal stressors, low levels of physical activity and weight loss, along with psychosocial perceptions of health and well being (see Walston, 2005 for a recent review). Available data suggest that, in the not too distant future, there 
will be increasing numbers of ever older elders in need of assistance with ADLs/IADLs, long term care, and appropriate housing. How these elders will be cared for, housed, and monitored will in large part determine their survival and well being (Lawton, 1980).

\section{Physiological Anthropology}

Physiological anthropologists are uniquely positioned to contribute to developing new standards for care, housing, monitoring, and design of environments for elders (Crews, 2005). Physiological anthropologists already focus on designing interior and exterior furnishings, along with lighting, color schemes, and housing appropriate for adults. They have contributed to improvements in everything from auto interiors to the size of buttons on cell phones and from lighting to acoustical environments for the general population (reviewed in Crews, 2005). Now is the time for physiological anthropologists to turn these techniques and skills toward improving and designing spaces and places for elders (Crews 2005; Zavotka and Teaford, 2004). One method for doing so may be to work with Interior Design professionals who are knowledgeable about "Universal Design" elements as promoted in the US for compliance with the Americans with Disabilities Act (Null and Cherry, 1996) and improve accesibility for all.

\section{The Needs of Elders}

Elders need spaces conducive to their activity patterns and declining sensory perceptions. As early as 1980, Lawton suggested that by proper design with fewer physical barriers and more attention to the needs of elders, it should be possible to improve the functional abilities of many seniors by having the environment accommodate to them rather than the individual accommodating to the environment. Based upon observed patterns of frailty and disability among elders, Lawton and Simon (1968) formulated the "environmental docility hypothesis." They observed that the less competent an individual becomes, the more influential the environment is on limiting that person's capabilities. Thus, to improve the capabilities and well-being of elders, Lawton (1980) suggests it is necessary to design environments so as to enhance opportunities for independence and self-reliance. Multiple design features may improve the physical and mental wellbeing of elders just as they enhance the well-being of the young adults used as subjects in most physiological anthropology studies. Among these are what have come to be known as features of Universal Design (Null and Cherry, 1996; Zavotka and Teaford, 2004).

\section{Universal Design}

Most ADLs (bathing dressing, ambulation, toileting, feeding and transferring) take place in the bathroom, kitchen, and traffic areas (halls and doorways/entryways) of a home. In the US, construction and design of these spaces is steeped in tradition and an apprentice trade culture that have perpetuated home features that are not the most functional. As pointed out by Boschetti (2002), except for changes due to technology and style trends, kitchen and bath design standards established by the Small Homes Council in 1964 have remained basically unchanged ever since. Decisions for the design and construction of these areas are usually controlled by the builder/contractor and are the most standardized parts of a residence. For example, the standard kitchen counter is $36^{\prime \prime}$ high and 24" deep; exterior doors are $36^{\prime \prime}$ wide and interior doors $28^{\prime \prime}$ to $30^{\prime \prime}$ wide; tables are $28^{\prime \prime}$ to $30^{\prime \prime}$ high with chair seat height at $16^{\prime \prime}$ to $17^{\prime \prime}$ (Cheever, 1996).

Strangely, many of these size standards were based on anthropometrical measures of able-bodied, healthy US Military men from WW2 (Department of Defense, 1991). As indicated by the Department of Defense (1991), lack of data on the entire U.S. citizen population presents a serious problem for designers. Household furnishings and features based on these standards fail to meet the needs of most people (DeMerchant and Beamish, 1995) and clearly do not meet the needs of older adults, who as a group are shorter, less flexible, have greater fat mass, and less muscular mass, and are not as strong as younger cohorts. (Poehlman et al., 1995; Janssen et al., 2000).

Critical anthropometrical measures used in the design of functional household furnishings include standing elbow height, seated elbow height, vertical reach, popliteal length, buttock popliteal length, standing and seated eye height, and hand size (Null and Cherry, 1996; Panero and Zelnik, 1979). Designers must also take into consideration the strength and flexibility of individuals. If the design does not address an individual's physical attributes, ADL functioning can be compromised. For example, for someone to easily feed himself or herself, ergonomists recommend that dining chairs should be 1 inch shorter than the popliteal length and a dining table be the same height as the seated elbow height (Panero and Zelnik, 1979). Based on these criteria and standard anthropometrical data for older women, chair seat height should range from $12.5^{\prime \prime}$ to $16.2^{\prime \prime}$ and corresponding table height from $20^{\prime \prime}$ to $27^{\prime \prime}$. An older women using a standard table (30") and chair (17") would need to slump in her chair for her feet to touch the floor and raise her elbow above shoulder level to clear the table (Panero and Zelnik, 1979). One can conclude that for many older women, the current dining environment is not conducive to supporting the ADL of feeding oneself. Similar examples could be drawn for bathing in a standard tub/shower, using the toilet, reaching clothes in a closet, or transferring from a bed to a chair.

Human factors research on the built environment has concentrated primarily on the workplace, while concerns about functioning at home have centered on persons with disabilities. Since the early 1970's various groups have developed standards, guidelines and regulations to make public buildings more accessible (See US Department of Justice: A Guide to 
Disability Rights Laws for a summary of U.S. legislation). More recently the design community has recognized that persons' sizes and abilities represent more of a continuum. That is, people of the world cannot simply be divided into the abled and the disabled. Good environmental design reflects a variety of user needs and accommodates variation.

Universal Design was coined by Ron Mace (1998) to reflect a type of design allowing all users to be accomodated. Under his leadership, the Center for Universal Design at North Carolina State University defined universal design as "...the design of products and environment to be useable by all people, to the greatest extent possible, without the need for adaptation or specialized design. The intent of universal design is to simplify life for everyone by making products, communications, and the built environment more useable by as many people as possible at little or no cost." (Center for Universal Design, 2005). Universal design benefits people of all ages and abilities. The seven major principles of universal design indicate that a product or feature should 1) provide equitable use, 2) be flexible in use, 3 ) be simple and intuitive to use, 4) convey perceptible information, 5) provide tolerance for error, 6) require low physical effort, 7) provide size and space for approach and use of the feature (Center for Universal Design, 2003).

Universal design has roots in both the disability and design communities. Trachtmen et al. (1999) indicate that the disabled hope that a nationwide embracing of universal design will provide better products for them, while designers are seeking a venue for achieving good design. What also makes universal design so attractive is that it is a concept or philosophy not an enforceable code. This allows designers to be more flexible in meeting user needs. In public spaces, design standards set by federal and state regulations must still be met, but the universal design concept also allows designers to creatively approach solutions. In most cases, products or environments that are universally designed go beyond the minimal requirements of accessibility (Trachtmen et al., 1999). Universal design differs from accessible design in that it provides permanent, attractive features that everyone would find acceptable in their home (Null, 2001).

\section{Aspects of Universal Design}

Extensive literature providing guidelines and suggestions for the design of universal homes is available (see Guetzko and White, 1991; Regnier and Pynoos, 1987; Pynoos and Regnier, 1991; AARP, 1996; Yearns, 2001, 2000; Null, 2001; Center for Universal Design, 2005 for extensive lists), and can not be reviewed in its entirety here. A summary of features most directly related to the ADL's and IADL's of elders is included here. A primary concern is the ability to safely bath or shower one's self. In the bath and shower, basic UD needs are products that limit falls and injuries. Such accommodations include rollin or walk-in shower, grab bars in shower or tub area, shower seats, a handheld adjustable showerhead, lever faucet handles, temperature limiting devices, no slip flooring, a vanity at 32 34 " above the floor with lever faucet handles, a seating area at vanity, and an emergency call system. Transferring is integral to independence and closely associated with bathing, showering, toileting, and eating. Some considerations here include shower seats or a roll in shower so transferring is not necessary, comfortable toilet height and adequate space, grab bars as needed, and beds at popliteal height or slightly higher to allow easier independent transfers.

Toileting, a separate ADL from bathing/showering requires that the toilet be of proper height, have a $60^{\prime \prime}$ diameter floor space for easy turning, and grab bars appropriately installed. To remain independent, it is necessary to prepare meals and a number of UD considerations are necessary in the kitchen. These include a variety of multilevel work surfaces at 30", 34", and $36 "$ above the floor, side-by-side refrigerator with ice/water dispenser on door for ease of access, electric cook top on the stove with an opening below to accommodate a wheelchair or other device, and front controls, a separate oven at elbow or shoulder height, a microwave oven at elbow or shoulder height, an elevated dishwasher ( 8 " to $9^{\prime \prime}$ above floor) with easy to read and manipulate controls, single lever faucets, large appliance controls with contrasting large text, D-shaped door and drawer handles, wall cabinets or primary storage located between $22^{\prime \prime}$ and $56^{\prime \prime}$ from the floor, and base cabinets with large drawers or pull-out shelves and a seated work area at the sink. In the bedroom, adjustable height closet systems with multi-level shelves and walk-in closet with 36" door and 48" floor space are important aspects of UD. Mobility becomes a major concern with increasing frailty and is improved by attention to adequately wide doors of $32-36^{\prime \prime}$ width with thresholds $1 / 4^{\prime \prime}$ or shorter, lever door handles, low level loop carpet or hard surface flooring (non slip, non-glare), contrasting color values between floor and baseboard or furniture, no step entry (landscaped no step). In addition, the bedroom, bath, kitchen, and laundry should all be located on the 1st floor for ease of access and either key or remote control lock systems should be installed. Additionally, handrails on both sides of all stairs in the home allow easier access to other floors. The ability to feed one's self is another important aspect of independent living. In the dining room proper consideration to seat and table height, with the seat 1 " lower then popliteal height and the table at the same height as the individual's seated elbow height, along with contrasting colors of dishes, table, and floor provide improved abilities to see edges and items. A final area of consideration is adequate lighting. As a first consideration, increased lighting with greater brightness is needed for older adults who may need up to 4 times as much light as young individuals. In addition, outlets and switches should be located between $18^{\prime \prime}$ and $48^{\prime \prime}$ above the floor and replaced with rheostat/dimmer switches, touch or sound controlled lamps should be used, and adequate night lighting is needed to provide for safe walking.

Adoption of such universal design features will require a rethinking of many standardized features in homes, along with a revolution in the minds of builders, product manufacturers, 
and consumers. In the US, national organizations such as NAHB (National Association of Home Builders) and AARP have spearheaded educational projects on universal design. At the local level however, people remain reluctant to change. Builders and consumers often lack knowledge about the variety of design options available (Price et al., 2004; Wagnild, 2001). Furthermore, older adults are not convinced that universal design will really make a difference in their daily lives. Research indicates that older adults would be more likely to make needed changes in their homes if they understood that the change would truly make a difference. (Ohta and Ohta, 1997; Sherman and Combs, 1997).

Continued Research on UD is needed to determine what effect universally designed environments have on ADLs, allostatic load, and other markers of frailty among elders. Additional research should address which features or combinations of features are most effective in providing support for ADLs and IADLs and maintaining independent living. Finally, it is not yet clear which UD features are most effective for enhancing the well being of particular groups of people. This area of research may show that persons of all ages do not benefit equally from some aspects of UD, while others experience large benefits. Physiological anthropologists are well positioned to conduct continued research on the benefits of UD and the effects of UD on additional cohorts. Experimental protocols aimed at determining the proper lighting environment, or color and decorating schemes, or temperatures for work, sleep, and leisure, or optimum sizes for handheld tools and instruments may be easily adapted to the study of UD and its effects on young and old.

\section{Discussion and Conclusions}

The future of physiological anthropology will be enriched by attention to ergonomic and universal design considerations for elders, in attention to current foci on young adults. The use of universal design considerations in the development of housing and infrastructure for all ages is a natural addition to physiological anthropologists' current interests in enhancing built and artificial environments (see "The 21st Century COE Program, International. Symposium on Design of Artificial Environments", December 2-3, 2004, Fukuoka, Japan, Abstracts). As we all age, attention to these considerations should improve all of our lives and our functional abilities by accommodating environments to us rather than us having to accommodate to under-designed environments. Universal design features likely will enhance feelings of well being and safety among not only elders, but all citizens. UD will permit more elders to age-in-place, rather than requiring retirement communities and nursing homes to provide their essentials of life. By participating in the design of artificial and built environments, physiological anthropologists will contribute to better living conditions for all citizens, and to reducing the disabilities and frailty, and health care costs, that are today associated with long life.

\section{References}

American Association of Retired Persons (AARP) (1996) List of home modifications that can enhance comfort, safety, and independence. Consumer affairs section of program coordination and development. AARP, Washington, D.C.

Amdam G (2005) Social control of aging and frailty in bees. In Carey JR, Robine JM, Michel JP, Chrieten Y eds. Longevity and frailty. Springer-Verlag, New York, 17-26

Arking R (2005) Biology of aging: observations and principles. 3rd ed., Oxford University Press, New York

Beall CM (1994) Aging and adaptation to the environment. In Crews DE, Garruto RM eds. Biological anthropology and aging: perspectives on human variation over the life span. Oxford University Press, New York, 339-369

Boshchetti MA (2002) An observational study of older people's use of standard US kitchens. Housing and Society 29: 1-12

Brock DB, Guralnik JM, Brody JA (1990) Demography and epidemiology of aging in the United States. In Schneider EL, Rose JW eds. Handbook of the biology of aging, Academic Press, Inc., San Diego, 3-23

Carey JR, Papadopoulos N (2005) The medfly as a frailty model: implications for biodemographic research. In Carey JR, Robine JM, Michel JP, Chrieten Y eds. Longevity and frailty. Springer-Verlag, New York, 1-15

Center for Universal Design (1997) Principles of universal design. Center for Universal Design, North Carolina State University, Raleigh

Cheever EM (1996) Volume 4: Kitchen planning standards and safety criteria. National Kitchen and Bath Association, Hackettstown, 27-45

Crews DE (2005) Artificial environments and an aging population: designing for age-related functional losses. J Physiol Anthropol Appl Hum Sci 24: 103-109

Crews DE (2003) Human Senescence: Evolutionary and Biocultural Perspectives. Cambridge University Press, New York

Demerchant EA, Beamish JO (1995) Universal design in residential spaces. Housing and Society: 22: 77-91

Department of Defense (1991) Military handbook anthropometry of U.S. military personnel. DOD-HDBK743A. US Government Printing Office, Washington, D.C.

Federal Interagency Forum on Aging Related Statistics (FIFARS) (2000) Older Americans 2000: key indicators of well-being. US Government Printing Office, Washington, D.C.

Guetzko B, White B (1991) Kitchen designers as change agents in planning for aging in place. Home Economics Res J 20: $172-182$

Harper GJ, Crews DE (2000) Aging, senescence, and human variation. In Stinson S, Huss-Ashmore R, O'Rourke D, eds. Human biology: an evolutionary and biocultural Perspective. Wiley-Liss, New York, 465-505

Janssen I, Heymsfield SB, Wan Z, Ross R (2000) Skeletal 
mass and distribution in 468 men and women aged 18-88 yrs. J Appl Physiol 89: 81-88

Katz SA, Ford AB, Moskowitz RW, Jackson BA, Jaffee MW (1963) Studies of illness in the aged. The index of ADL: a standardized measure of biological and psychosocial function. J Am Med Assoc 185: 94-101

Lawton MP (1980) Environment and aging. Brooks-Cole, Monterey

Lawton MP, Simon B (1968) The ecology of social relationships in housing for the elderly. Gerontologist 8: 109-115

Mace R (1998) Universal design: housing for the lifespan of all people. U.S. Department of Housing and Urban Development, Washington D.C.

Manton KG, Corder L, Stallard E (1997) Chronic disability trends in elderly United States populations: 1982-1994. Proc Nat Acad Sci USA 94: 2593-2598

Murphy CT (2005) A review of genes that act downstream of the DAF-16 FOXO transcription factor to influence the lifespan of C. elegans. In Carey JR, Robine JM, Michel JP, Chrieten Y eds. Longevity and frailty. Springer-Verlag, New York 27-37

Null R, Cherry K (1996) Universal design: creative solutions for ADA compliance. Professional Publications, Belmont

Ohta RJ, Ohta BM (1997) The elderly consumer's decision to accept or reject home adaptations: Issues and perspectives. In Lanspery S, Hyde J eds. Staying put: adapting the places instead of the people. Baywood Publishing, Amityville, 79-90

Omran AR (1972) The epidemiologic transition: a theory of the epidemiology of populations change. Millbank Memorial Fund Q 49: 509-538

Panero J, Zelnik M (1979) Human dimension and interior space. Whitney Library of Design, New York

Poehlman ET, Toth MJ, Bunyard LB (1995) Physiological predictors of increasing total and central adiposity in aging men and women. Arch Intern Med 155: 2443-2448

Poehlman ET, Toth MJ, Bunyard LB, Gardner AW, Donaldson KE, Colman E, Fonong Rakowski W, Pearlman DN (1995) Demographic aspects of aging: current and future trends. In Reichel W ed. Care of the elderly: clinical aspects of aging. Baltimore, Williams and Wilkins, 488-495

Pynoos J, Regnier V (1991) Improving residential environments for frail elderly: bridging the gap between theory and application. In Birren JE, Lubbes JE, Rowe J, Deutchmen D eds. The concept and measurement of quality of life in the frail elderly. Academic Press, San Diego, 91-119

Regnier V, Pynoos J (1982) Housing the Elderly. Elsevier, New York

Sherman S, Combs R (1997) Characteristics related to elderly persons' perceived difficulty of remaining in their homes. Family Consumer Sci Res J 26: 59-74

Starkloff C (2001) A consumer's perspective on aging: challenges for independent living. Rehabilitation Education. 15: 439-448

Susman R, Riley MW (1985) Introducing the oldest old. Millbank Memorial Fund Q 63: 177-186

Teitlebaum MS (1975) Relevance of demographic transition theory for developing countries. Science 188: 420-425

Trachtman L, Mace RL, Young LC, Pace RJ (1999) The universal design home: are we ready for it? In Taira E, Carlson $\mathrm{J}$ eds. Aging in place: designing, adapting, and enhancing the home environment. The Haworth Press, New York, 1-18

U.S. Department of Justice (2004) A guide to disability rights laws. http://www.usdoj.gov/crt/ada/cguide.htm

Waagnild G (2001) Growing old at home. Journal of Housing for the Elderly 14: 71-84

Yearn M (2000) The welcoming home. Iowa State Extension Service, Ames, PM 1804

Yearn M (2001) Retirement: secure your dreams. Iowa State Extension Service, Ames, PM 1824

Zavotka S, Teaford M (1997) The design of shared social spaces in assisted living for older adults. J Interior Design 23: $2-16$

Received: September 13, 2005

Accepted: October 17, 2005

Correspondence to: Douglas E. Crews, Departments of Anthropology, The Ohio State University, 124 W. 17th Ave244 Lord Hall, Columbus, OH 43201, USA

Phone: + 1-614-292-1329

Fax: + 1-614-292-4155

e-mail: Crews.8@osu.edu 